\title{
Hepatocellular carcinoma: a review
}

This article was published in the following Dove Press journal:

Journal of Hepatocellular Carcinoma

5 October 2016

Number of times this article has been viewed

Julius Balogh
David Victor III',
Emad H Asham ${ }^{1,2}$
Sherilyn Gordon
Burroughs
Maha Boktour
Ashish Saharial,2
Xian Li ${ }^{1,2}$
R Mark Ghobrial',2
Howard P Monsour Jr',3,4
'Sherrie and Alan Conover Center
for Liver Disease and Transplantation,
${ }^{2}$ Division of Transplantation,
Department of Surgery, ${ }^{3}$ Department
of Gastroenterology and Transplant
Hepatology, ${ }^{4}$ Department of Medicine,
Houston Methodist Hospital,
Houston, TX, USA

Houston, TX, USA
Correspondence: Howard P Monsour Jr Department of Gastroenterology and Transplant Hepatology, Houston Methodist Hospital, 6550 Fannin Street, Smith Tower I00I, Houston, TX 77030, USA

Email HPmonsour@houstonmethodist.org
Abstract: Hepatocellular carcinoma (HCC) is the most common primary liver malignancy and is a leading cause of cancer-related death worldwide. In the United States, HCC is the ninth leading cause of cancer deaths. Despite advances in prevention techniques, screening, and new technologies in both diagnosis and treatment, incidence and mortality continue to rise. Cirrhosis remains the most important risk factor for the development of $\mathrm{HCC}$ regardless of etiology. Hepatitis B and $\mathrm{C}$ are independent risk factors for the development of cirrhosis. Alcohol consumption remains an important additional risk factor in the United States as alcohol abuse is five times higher than hepatitis C. Diagnosis is confirmed without pathologic confirmation. Screening includes both radiologic tests, such as ultrasound, computerized tomography, and magnetic resonance imaging, and serological markers such as $\alpha$-fetoprotein at 6-month intervals. Multiple treatment modalities exist; however, only orthotopic liver transplantation (OLT) or surgical resection is curative. OLT is available for patients who meet or are downstaged into the Milan or University of San Francisco criteria. Additional treatment modalities include transarterial chemoembolization, radiofrequency ablation, microwave ablation, percutaneous ethanol injection, cryoablation, radiation therapy, systemic chemotherapy, and molecularly targeted therapies. Selection of a treatment modality is based on tumor size, location, extrahepatic spread, and underlying liver function. HCC is an aggressive cancer that occurs in the setting of cirrhosis and commonly presents in advanced stages. HCC can be prevented if there are appropriate measures taken, including hepatitis B virus vaccination, universal screening of blood products, use of safe injection practices, treatment and education of alcoholics and intravenous drug users, and initiation of antiviral therapy. Continued improvement in both surgical and nonsurgical approaches has demonstrated significant benefits in overall survival. While OLT remains the only curative surgical procedure, the shortage of available organs precludes this therapy for many patients with HCC.

Keywords: hepatocellular carcinoma, cirrhosis, $\alpha$-fetoprotein, orthotopic liver transplantation

\section{Introduction}

Hepatocellular carcinoma ( $\mathrm{HCC}$ ) is the most common primary liver malignancy and is a leading cause of cancer-related death worldwide. In the United States, HCC is the ninth leading cause of cancer deaths. ${ }^{1}$ A total of 30,640 new liver and intrahepatic bile duct cancers were estimated to occur in 2013 in addition to 21,670 deaths. ${ }^{2}$ HCC occurred more often in males than females $(2.4: 1)$, with a higher incidence in Eastern and Southern Asia, Middle and Western Africa, Melanesia, and Micronesia/Polynesia. ${ }^{3}$ The age-adjusted incidence of liver cancer has risen from 1.6 per 100,000 individuals to 4.6 per 100,000 individuals among American Indians and Alaskan Natives followed by blacks, Whites, and Hispanics. ${ }^{4}$ There are pockets in the United States where certain ethnic groups have 
significantly increased incidence of HCC. Importantly, the incidence of $\mathrm{HCC}$ will continue to escalate as hepatitis $\mathrm{C}$ reaches its maturity and as nonalcoholic steatohepatitis (NASH) and obesity become more prevalent in the United States.

\section{Risk factors}

Chronic liver disease and cirrhosis remain the most important risk factors for the development of HCC of which viral hepatitis and excessive alcohol intake are the leading risk factors worldwide.

Chronic viral hepatitis can lead to cirrhosis and/or HCC. Hepatitis $\mathrm{B}$ and $\mathrm{C}$ are the most common causes of chronic hepatitis in the world. Hepatitis B virus (HBV) is a double-stranded, circular DNA molecule with eight genotypes (A to H). Genotypes $\mathrm{A}$ and $\mathrm{D}$ are more common in Europe and the Middle East, while genotypes $\mathrm{B}$ and $\mathrm{C}$ are more common in Asia. ${ }^{5}$ Hepatitis $\mathrm{B}$ is transmitted via contaminated blood transfusions, intravenous injections, and sexual contact. Vertical transmission from mother to fetus is the leading cause for HBV infection worldwide. Five percent of the world's population is infected with hepatitis B. ${ }^{6}$

Several epidemiological studies have demonstrated significant hepatocarcinogenicity with chronic HBV infection. ${ }^{7}$ Hepatitis B carriers have a $10 \%-25 \%$ lifetime risk of developing HCC. Unlike other causes of chronic hepatitis, $\mathrm{HBV}$ is unique in that $\mathrm{HCC}$ can develop without evidence of cirrhosis. ${ }^{2}$ Genotype $\mathrm{C}$ has been associated with a higher risk of HCC than genotypes A, B, and D. ${ }^{8}$ Active infection with HBV carries an independent risk of HCC with HBV DNA levels $>10^{5} / \mathrm{mL}$ viral copies associated with a 2.5-3 times increased risk of developing HCC in 8-10 years follow-up. ${ }^{9}$ Hepatitis B surface antigen ( $\mathrm{HBsAg}$ ) is not the only hematological marker that carries a significant risk for development of HCC. Patients with positive hepatitis B core antibody (anti-HBc) who are HBsAg-negative also remain at risk for development of HCC. The hepatocarcinogenicity of HBV can be significantly reduced with antiviral treatment for hepatitis B. Suppression of the virus can result in a significant 5-year reduction of the incidence of HCC from 13.7\% (controls) to $3.7 \%$, with the greatest reduction occurring in cirrhotic patients. ${ }^{10}$ The use of HBV vaccination has resulted in significant declines in the incidence of HCC from HBV. ${ }^{11}$ The East Asian neonatal vaccination program is estimated to result in a $70 \%-85 \%$ decrease in the incidence of hepatitis B-related HCC. ${ }^{12}$ Despite perinatal immunization, $5 \%-10 \%$ of infants remain at risk of acquiring hepatitis $B$ infection. The use of nucleoside analogs in treating chronic hepatitis B mothers in their third trimester of pregnancy has demonstrated superiority to vaccination alone in preventing neonatal transmission. ${ }^{13,14}$
Hepatitis $\mathrm{C}$ virus (HCV) is a small, single-stranded RNA virus, which exhibits high genetic variability. ${ }^{15}$ There are six different genotypes of HCV isolated. Genotypes I, II, and III are predominant in the Western countries and the Far East, while type IV is predominant in the Middle East. The highest rates of chronic hepatitis $\mathrm{C}$ infection occur in Egypt (18\%), with lower rates occur in Europe $(0.5 \%-2.5 \%)$, the United States $(1.8 \%)$, and Canada $(0.8 \%) .{ }^{16}$ Once infected with $\mathrm{HCV}, 80 \%$ of patients progress to chronic hepatitis, with $\sim 20 \%$ developing cirrhosis. ${ }^{17}$ In hepatitis $\mathrm{C}$, the development of HCC occurs almost exclusively in the liver with established cirrhosis; however, in the HALT-C trial, 8\% of HCC occurred in patients with only advanced fibrosis. ${ }^{18}$ Dual infection with $\mathrm{HBV}$ and HCV in a cirrhotic patient increases the risk of HCC with an odds ratio (OR) of 165 compared to 17 for hepatitis $\mathrm{C}$ and 23 for hepatitis B alone. ${ }^{2,19}$ A synergistic effect with alcohol increases the incidence of $\mathrm{HCC}$ between 1.7- and 2.9-fold when compared to $\mathrm{HCV}-\mathrm{HCC}$ alone. ${ }^{20,21}$ The risk of $\mathrm{HCC}$ is reduced significantly in patients who obtained a sustained viral response after treatment of $\mathrm{HCV}$ with a $54 \%$ reduction in all-cause mortality. ${ }^{22}$ While advances in medications recently have made treating $\mathrm{HCV}$ easier, vaccinations against the virus remain elusive.

Alcohol consumption remains an important risk factor for the development of HCC. ${ }^{23}$ The relationship between alcohol and liver disease correlates with the amount of alcohol consumed over a lifetime, with heavy alcohol use rather than social drinking being the main risk of $\mathrm{HCC}^{24}$ The prevalence rate of alcohol abuse in the United States is five times higher than that of hepatitis $\mathrm{C} .{ }^{25}$ Alcohol abuse accounts for $40 \%-50 \%$ of all HCC cases in Europe. ${ }^{26}$ Studies in Europe reported an increase in the relative risk of developing liver disease above $7-13$ drinks per week in women and 14-27 drinks per week in men. ${ }^{25,27}$ In the United States, studies showed that the risk of liver cancer is increased twoto fourfold among persons drinking more than $60 \mathrm{~g} / \mathrm{d}$ of ethanol. ${ }^{28} \mathrm{~A}$ meta-analysis of 19 prospective studies showed that consumption of three or more drinks per day resulted in a $16 \%$ increase risk of liver cancer and consumption of six or more drinks per day resulted in a $22 \%$ increase risk. ${ }^{29}$

\section{Diabetes and nonalcoholic fatty liver disease}

Sixty percent of patients older than 50 years with diabetes or obesity are thought to have NASH with advanced fibrosis. ${ }^{30}$ Chronic medical conditions such as diabetes mellitus and obesity increase the risk of HCC. Diabetes mellitus directly affects the liver because of the essential role the liver plays in glucose metabolism. It can lead to chronic hepatitis, fatty 
liver, liver failure, and cirrhosis. Diabetes is an independent risk factor for HCC. ${ }^{19,31}$ Patients with diabetes have between a 1.8- and 4-fold increased risk of HCC. When compared to $\mathrm{HCV}$, NASH-related HCC liver transplants increased by nearly four times in the decade from 2002 to 2012. ${ }^{32}$ In 2006, ElSerag et $\mathrm{al}^{33}$ reviewed several cohort and case-control studies showing that diabetes mellitus is significantly associated with HCC. Hyperinsulinemia has been associated with a threefold increased risk of HCC. It is believed that the pleotropic effects of insulin that regulate the anti-inflammatory cascade and other pathways inducing cellular proliferation play a role in carcinogenesis. Insulin-like growth factor and insulin receptor substrate-1 promote cellular proliferation and inhibit apoptosis, respectively. ${ }^{34,35}$ It is well-known that obesity is associated with many hepatobiliary diseases, including nonalcoholic fatty liver disease (NAFLD), steatosis, and cryptogenic cirrhosis all of which can lead to the development of HCC..$^{36,37}$ Obesity itself increases the risk of $\mathrm{HCC}$ to 1.5 - to 4 -fold. The relative risk of $\mathrm{HCC}$ is $117 \%$ for overweight subjects and $189 \%$ for obese patients. ${ }^{38}$ The majority of HCC-NAFLD occurs in men. Compared to women, men developed HCC with less fibrosis and cirrhosis. ${ }^{39}$ The mean age of presentation is 70 years. Up to $50 \%$ of cases of NAFLD-related HCC may occur in the absence of cirrhosis. ${ }^{29}$ These tumors tend to have lower $\alpha$-fetoprotein (AFP) synthesis but are more likely to have elevated des- $\gamma$ carboxy prothrombin (DCP) than HCV-related HCC. ${ }^{40,41}$

\section{Other predisposing conditions}

Sex may play a role in the development of HCC. HCC occurs more often in males, with a ratio of $2: 1-4: 1$; however, this may not be due to sex alone. ${ }^{42}$ Males are more likely to be infected with viral hepatitis, consume greater quantities of alcohol, smoke cigarettes, and have a higher body mass index than women. It may be the higher testosterone levels that account for the higher incidence in males. It is known that high testosterone levels have been linked to HCC in hepatitis $\mathrm{B}$ carriers and to advanced hepatic fibrosis in males with chronic hepatitis $\mathrm{C}$ infection. ${ }^{43,44}$ Elevated testosterone or intake of anabolic steroids has been associated with an increased incidence of $\mathrm{HCC}$ and liver adenomas.

Aflatoxin produced by Aspergillus species (molds) found on grains, corn, peanuts, or soybeans stored in warm humid conditions is a potent hepatocarcinogen. The risk of $\mathrm{HCC}$ with aflatoxin is dependent on the dose and duration of exposure. Aflatoxin exposure is more prevalent in rural United States. Aflatoxin exerts a synergistic effect on hepatitis $\mathrm{B}$ - and $\mathrm{C}$-induced liver cancer, the risk being 30 times greater with chronic hepatitis B plus aflatoxin exposure than with aflatoxin exposure alone. ${ }^{45}$ The most potent aflatoxin, AFB1, when removed from the environment has resulted in a reduction of the incidence of HCC. ${ }^{46}$

Metabolic and genetic diseases associated with HCC include hemochromatosis, Wilson's disease, $\alpha-1$ antitrypsin disease, tyrosinemia, glycogen-storage disease types I and II, and porphyrias.

The risk of HCC with hereditary hemochromatosis is estimated to be between 100- and 200-fold ${ }^{47}$ Other iron overload states such as thalassemia have not only been associated with HCC but also have a high prevalence of HCV that may contribute to the increased risk of primary liver cancer. South African blacks who consume beer brewed in nongalvanized steel drums have increased iron stores leading to an increase in the risk of HCC 10 times that of people with normal iron stores. $^{48,49}$

Other risk factors may include smoking. Cigarette smoking is associated with a significant increase in the development of HCC. A recent meta-analysis that reviewed the association between smoking and liver cancer demonstrated an OR of 1.6 (95\% confidence interval [CI], 1.3-1.9) for current smokers and 1.5 (95\% CI, 1.1-2.1) for former smokers. Studies investigating the use of oral contraceptive pills and the risk for development of HCC have previously been inconclusive; however, a recent review of six studies showed a significant increase in $\mathrm{HCC}$ risk with a longer duration (>5 years) of exposure to oral contraceptives. ${ }^{50}$

\section{Screening}

Surveillance (Table 1) for HCC should have the goal of decreasing mortality and improving patient outcomes. Studies have found a survival benefit for early screening of patients for HCC. ${ }^{51,52}$ Patients who are identified early consequently have multiple treatment options leading to improved outcomes. Defining the target population should be a priority in today's rising health care costs, as surveillance for the general population is not recommended. An intervention (screening modality) is considered clinically effective if it provides at least 100 days increase in longevity.

Table I Screening guidelines for HCC

\begin{tabular}{ll}
\hline Screening guidelines for HCC & \\
\hline All patients with cirrhosis (any age) & \\
Patients with $\mathrm{HBsAg}$ & \\
Asian females $>50 \mathrm{yr}$ & Males $>40 \mathrm{yr}$ \\
Africans/North American & Family history of HCC \\
Blacks $>20 \mathrm{yr}$ & \\
Non-Asians/Black females & Non-Asians/Black males $>40 \mathrm{yr}$ \\
$>50 \mathrm{yr}$ & with active disease \\
\hline
\end{tabular}

Notes: ${ }^{\mathrm{H}} \mathrm{HBV}-\mathrm{DNA}>100,000$ copies $/ \mathrm{mL}$ and/or elevated ALT. Data from Bruix et al. ${ }^{5}$ Abbreviations: $\mathrm{HCC}$, hepatocellular carcinoma; $\mathrm{HBV}$, hepatitis $B$ virus; $A L T$, alanine transaminase; $y r$, years. 
Cost-effectiveness would be defined as an intervention costing $<\$ 50,000 / y r$ of life gained. ${ }^{5}$ Screening intervals for HCC are based on the average tumor doubling time of 3-5 months and a cost-effective threshold of an expected annual incidence exceeding $1.5 \%$ in cirrhosis and $0.2 \%$ in noncirrhosis hepatitis B patients. ${ }^{53}$ Given these criteria, any patient with cirrhosis should be screened for HCC, although screening in autoimmune hepatitis cirrhosis and primary biliary cirrhosis may be of less value. Another exception to this rule may be patients with advanced/decompensated cirrhosis who are not transplant candidates. Their life expectancy is too short to receive any survival benefit from surveillance. ${ }^{54}$

Persistent infection with HBV, in both noncirrhotic and cirrhotic patients, is a major risk factor for developing HCC. HBV carriers have a 223-fold higher risk of developing HCC than noncarriers. ${ }^{55}$ The risk of HCC in Asian males exceeds the threshold for screening starting at the age of 40 years. $\mathrm{HCC}$ in Caucasians with hepatitis B is more related to virus inflammatory activity in noncirrhotic livers. ${ }^{56}$ Active disease is defined as an elevated alanine transaminase (ALT) and/or a high viral load (>20,000 IU/mL). Screening for noncirrhotic HBV in Caucasian males with active disease should start at 40 years of age, while screening for Asian and Caucasian females should start at 50 years of age. African noncirrhotic hepatitis $B$ carriers, in particular sub-Sahara Africans, have the highest incidence of HCC occurring particularly at a younger age. ${ }^{57}$ Screening in these individuals should begin at the time of diagnosis or upon reaching the age of 20 . Hepatitis B carriers with a family history of HCC are also at increased risk. The risk increases with age (23\% with $\mathrm{HCC}$ at 70 years vs $8.9 \%$ without family history) and the number of family members affected (risk 5.6 times with $>2$ family members). ${ }^{58}$ The age at which to start surveillance, however, has not been well-defined by guidelines. At our institution, we begin surveillance for males at age 40 and females at age 50 or 10 years before the index cancer developed in a family member.

\section{Screening modalities}

Modalities available for HCC screening include both radiographic tests and serological markers. Radiological tests commonly used for surveillance include ultrasonography (US), multiphase computerized tomography (CT), and magnetic resonance imaging (MRI) with contrast. US has historically been utilized to identify intrahepatic lesions since the early 1980 s. $^{59}$ Sensitivity of US imaging is variable, ranging from $35 \%$ to $84 \%$, and is operator and equipment dependent; however, studies have reported a specificity $>90 \%$ when used for screening. ${ }^{60,61}$ Small HCC nodules $\leq 2 \mathrm{~cm}$ represented $85 \%$ of the lesions that failed to be detected by US. ${ }^{62}$ Furthermore, central obesity hampers ultrasound's ability to detect small lesions. ${ }^{63} \mathrm{HCC}$ lesions exhibit increased arterialization as well as decreased presence of contrast agents during the portal phase of imaging (washout) on both CT and MRI scans. ${ }^{64}$ Tumors $\geq 2 \mathrm{~cm}$ are detected by $\mathrm{CT}$ and MRI at $90 \%$ sensitivity, while sensitivity detection of tumors between 1 and $2 \mathrm{~cm}$ is $65 \%$ and $80 \%-92 \%$ and that for tumors $<1 \mathrm{~cm}$ is $10 \%$ and $34 \%-71 \%$, respectively. ${ }^{65} \mathrm{CT}$ and $\mathrm{MRI}$ is preferred in patients who have equivocal results utilizing US as their initial modality.

AFP's main function is the regulation of fatty acids in both fetal and proliferating adult liver cells. ${ }^{55}$ Since 1968, AFP has been used as a serum marker for the detection of HCC. ${ }^{32}$ Several studies have evaluated the sensitivity and specificity of utilizing AFP with ranges of $21 \%-64 \%$ and $82 \%-93 \%$, respectively. ${ }^{65-69}$ One major disadvantage is that AFP levels can be falsely raised in patients who have active hepatitis but no evidence of HCC. The upper limit of normal that is often adopted is $20 \mathrm{ng} / \mathrm{mL}$ because AFP levels in healthy individuals rarely exceed this level. In chronic hepatitis $\mathrm{C}$ patients without HCC, AFP can be $>20 \mathrm{ng} / \mathrm{mL}$ in $16 \%$ of patients. ${ }^{70}$ Furthermore, the sensitivity of AFP $>20 \mathrm{ng} / \mathrm{mL}$ may have racial differences, being found to be $42.9 \%$ among blacks and $60 \%$ among nonblacks. ${ }^{71}$ AFP sensitivity is lower with small HCC lesions. It can be elevated in acute hepatitis, cirrhosis, colitis, germ cell tumors, and intrahepatic cholangiocarcinoma. AFP levels above $400 \mathrm{ng} / \mathrm{mL}$ can be considered definitive in diagnosing HCC, but sensitivity is lower at this higher cutoff value. ${ }^{55}$ Lin et $\mathrm{al}^{72}$ demonstrated that surveillance with AFP and ultrasound was cost-effective regardless of the incidence of HCC.

In 2011, American Association for the Study of Liver Diseases (AASLD) published updates to its guidelines for surveillance of HCC. Cost-effectiveness is achieved if the expected $\mathrm{HCC}$ risk exceeds $1.5 \%$ per year in patients with $\mathrm{HCV}$ and $0.2 \%$ per year in patients with HBV. Ultrasound is the most cost-effective modality when performed at 6-month intervals. Some studies show that 6-month ultrasound with AFP exceeds cost-effectiveness, while biannual AFP/annual contrast CT exceeds the threshold by $\$ 1,750 .^{72}$ AFP lacks adequate sensitivity and specificity for surveillance, and therefore surveillance has to be based on US examination every 6 months. ${ }^{53}$

While standard AFP levels are of variable benefit in identifying patients with HCC, other assays are available. Lens culinaris agglutinin-reactive fraction of $\alpha$-fetoprotein (AFP-L3) expressed as a percentage of AFP has been found to be elevated in patients with HCC. It is highly specific for $\mathrm{HCC}$ when AFP levels are $>20 \mathrm{ng} / \mathrm{mL}$. A level $>10 \%$ may identify patients with increased risk of developing HCC. AFP-L3 is associated with a more aggressive tumor, shorter 
doubling time, infiltrative growth pattern, vascular invasion, and intrahepatic metastasis. ${ }^{73}$

DCP is produced by malignant hepatocytes from an acquired posttranslational defect in vitamin K-dependent carboxylase system. The specificity of the DCP is $91 \%$ compared to $70 \%$ for AFP; however, sensitivity is low at $41 \% .{ }^{74}$ DCP normalizes with successful tumor resection. DCP levels $>125 \mathrm{mAU} / \mathrm{mL}$ is sensitive and specific for differentiating HCC from chronic hepatitis and cirrhosis. ${ }^{75}$ The highest accuracy for diagnosing HCC occurs when all three markers with appropriate cutoff values are used together. A $\mathrm{DCP}>40 \mathrm{mAU} / \mathrm{mL}+\mathrm{AFP}>20 \mathrm{ng} / \mathrm{mL}$ and AFP-L3 $>10 \%$ yield a sensitivity of $82.2 \%$ with a specificity of $82.4 \%{ }^{76}$

\section{Diagnosis}

To obtain the best treatment result for $\mathrm{HCC}$, early diagnosis is the key. Chronic hepatitis leads to the development of cirrhosis. Cirrhotic livers exhibit regenerative nodules, which result from increased proliferation of hepatocytes. Differentiation between these regenerative nodules and HCC can vary based on the size of the nodules. Nodules $<1 \mathrm{~cm}$ (Figure 1) detected via US that cannot be defined should be followed up with a repeat US in 3-4 months. Nodules $>1 \mathrm{~cm}$ detected via US should have further radiologic investigation including either contrast-enhanced triple or quadriphasic CT or MRI. The diagnosis of HCC is based on the contrast enhancement in the arterial phase (wash-in) followed by disappearance of the contrast in the venous phase (washout) (Figure 2). ${ }^{77} \mathrm{~A}$ recent metaanalysis of the diagnostic performance of CT and MRI for evaluating HCC has demonstrated that MRI has a higher per-lesion sensitivity than multidetector CT and should be the preferred imaging modality for the diagnosis of HCC in patients with chronic liver disease. ${ }^{78}$ If the first radiologic test is equivocal, then confirmation with a different technique is recommended. If the diagnosis still remains uncertain, a serum AFP level $>400 \mathrm{ng} / \mathrm{mL}$ has a high positive predictive value. ${ }^{79}$ Percutaneous biopsy should be limited to those nodules that are radiologically nontypical on CT or MRI for HCC. ${ }^{80}$

\section{Staging}

Stratification of patients diagnosed with HCC into groups is the primary aim of staging systems. Staging systems will assist

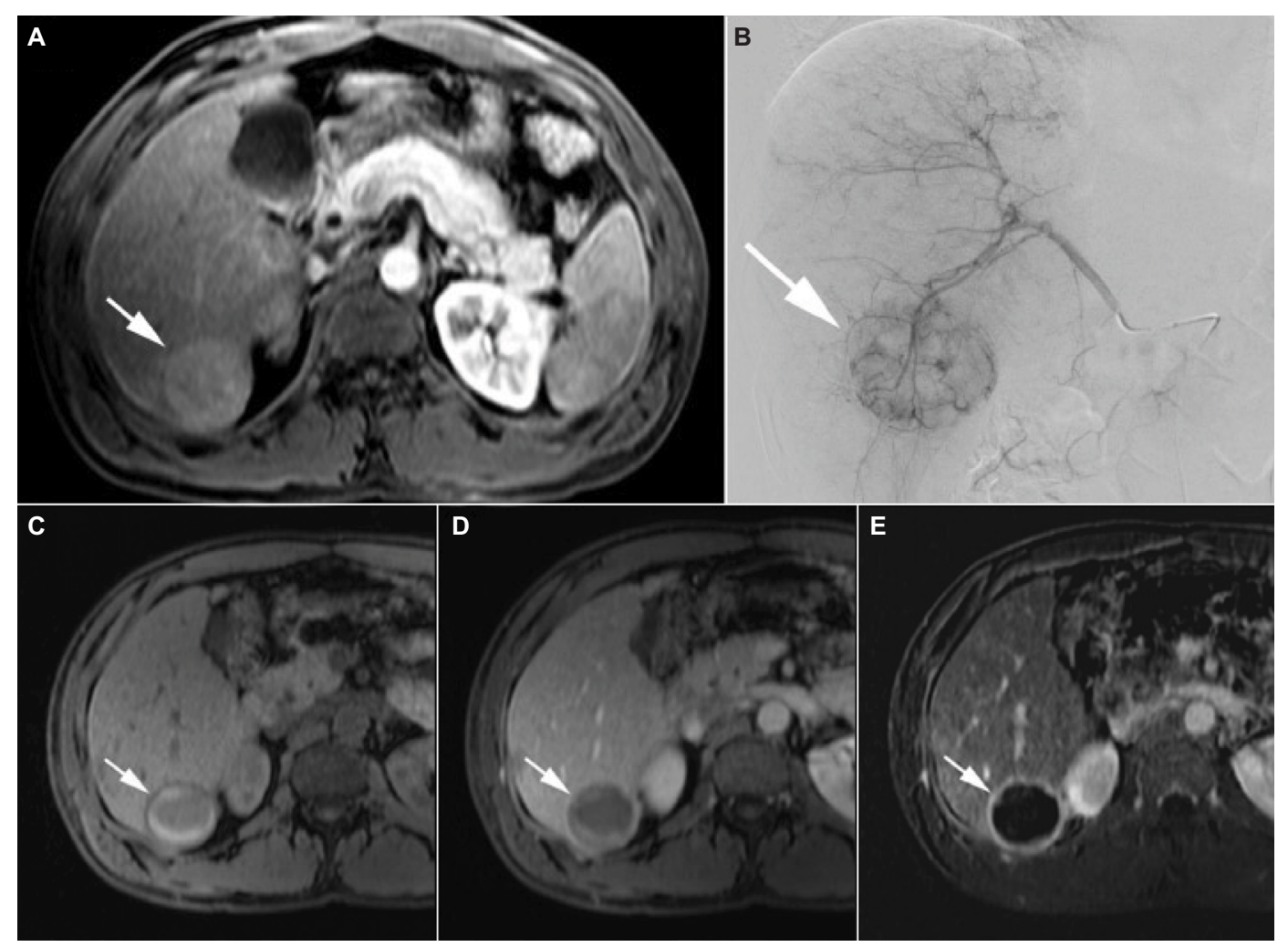

Figure I TACE.

Notes: Pretreatment MRI of a 43-year-old male with hepatitis $C$ shows (A) a 4-cm T2-hyperintense solitary mass (arrow [A-E]) in segment VI of the liver with enhancement features compatible with hepatocellular carcinoma. The patient was treated with TACE with drug-eluting beads (B). A follow-up MRI 6 months after TACE shows intrinsic TI peripheral hyperintensity $(\mathbf{C})$ within the treated lesion with no residual internal enhancement (D), confirmed on subtracted imaging (E). Reproduced from Cochrane Miller J. Bridging procedures prior to liver transplantation. Radiology Rounds. 2015; I3(I). ${ }^{145}$

Abbreviations: TACE, transarterial chemoembolization; MRI, magnetic resonance imaging. 


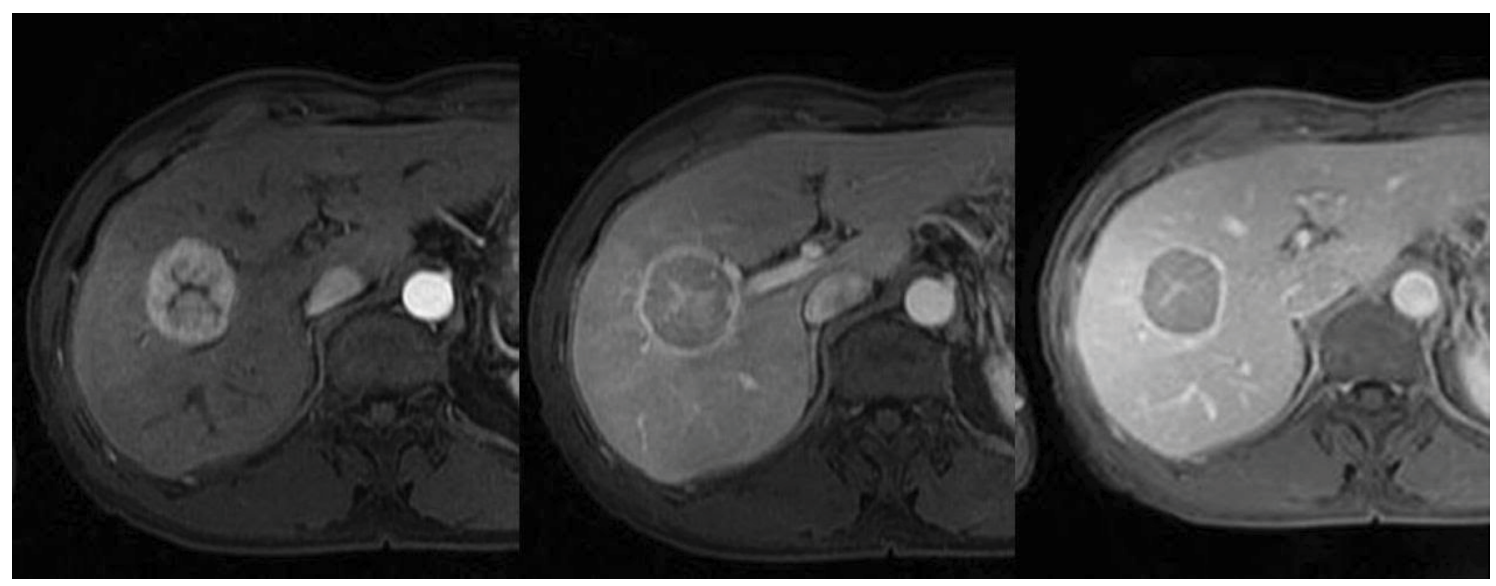

Figure 2 Typical HCC shows arterial phase hypervascularity with washout of contrast on portal venous and equilibrium phase. Note: There is delayed pseudocapsule enhancement.

Abbreviation: HCC, hepatocellular carcinoma.

in organizing patients into groups based on prognosis and can guide clinicians in a choice of therapy, aid patient counseling, and facilitate patient selection and randomization for research protocols. ${ }^{81}$ Currently, there are three clinical and four pathologic staging systems. Pathologic staging systems include the Liver Cancer Study Group of Japan, Japanese Integrated, Chinese University Prognostic Index, and American Joint Committee on Cancer/International Union Against Cancer Staging System. Clinical staging systems include the Okuda Staging System, Cancer of the Liver Italian Program score, and the Barcelona Clinic Liver Cancer Staging System (BCLC). The BCLC staging system is widely accepted in clinical practice and is also at the forefront of many clinical trials used to establish the effectiveness of new HCC drugs. ${ }^{53}$ The BCLC staging system has become the de facto staging system that is used. In the United States, there are additional staging systems commonly used, including the Model for End-Stage Liver Disease (MELD) score, the tumor-node-metastasis (TNM) staging system, or the simplified TNM staging system. ${ }^{82-85}$ In 2010, the AASLD published their recommendations regarding staging systems for HCC. Staging systems should best assess the prognosis of $\mathrm{HCC}$ in that a staging system should take into account tumor stage, liver function, and physical status. BCLC is the only system that takes into account all of these factors. ${ }^{5}$

CT scan of the chest, abdomen, and pelvis in addition to bone scan is vital to look for secondary disease and staging. Tumor characteristics such as size, maximum diameter, and number of lesions, location of tumors, vascular invasion, and any extrahepatic disease should be documented.

\section{Treatment}

Unfortunately, the diagnosis of HCC is too often made with advanced disease when patients have become symptomatic and have some degree of liver impairment. At this late stage, there is virtually no effective treatment that would improve survival. In addition, the morbidity associated with therapy is unacceptably high. The unfortunate truth is that many patients are not properly screened. In a study looking at Marketscan claims database, over 700,000 patients with at least one claim for NAFLD/NASH/HCV over one-quarter of those diagnosed with HCC had no knowledge of liver disease prior to their diagnosis. ${ }^{86} \mathrm{HCC}$ screening was regularly performed on $21.1 \%$ of NASH and $22.3 \%$ of hepatitis $\mathrm{C}$ patients in this study. Even when patients are followed by expert hepatologists at academic centers, up to one-third of the patients had inconsistent HCC surveillance. ${ }^{87}$ With proper screening and vigilance, many patients can and should be diagnosed with early disease and preserved liver function. Currently, there are several treatment options, both surgical and nonsurgical, that can have a positive impact on survival. ${ }^{88}$ The best outcomes are achieved when patients are carefully selected for each treatment option. Regardless of the treatment approach, patients with HCC require a multidisciplinary approach to care to ensure optimal outcome. The multidisciplinary team typically consists of a hepatologist, a radiologist, a pathologist, a medical oncologist, an interventional radiologist, a transplant surgeon, and a hepatobiliary surgeon. Each specialty will have unique contributions to ensure optimal long-term outcomes for patients with HCC.

\section{Surgical approaches Resection}

Surgical resection is the accepted treatment of choice for noncirrhotic patients and offers the best curative rate with a 5 -year survival of $41 \%-74 \%{ }^{89}$ The resectability of the 
tumor is dependent on the tumor size, location, underlying liver function, and whether or not the remaining liver volume will allow for resection without drastically increasing postresection morbidity and mortality. Resection is considered the first-line treatment as long as $\mathrm{R} 0$ resection can be accomplished. The candidates for this therapy are patients with a solitary tumor confined to the liver, no radiologic evidence of vascular invasion, and well-maintained liver function..$^{90,91}$ Optimum candidate selection is crucial to limit surgical morbidity and mortality. In patients with normal synthetic function, the size of the tumor does not necessarily affect the outcome when residual volume (volume of remaining liver) is adequate and technical aspects of the surgery are achievable. ${ }^{92}$ Operative mortality is affected by the presence $(10 \%)$ or absence $(5 \%)$ of cirrhosis..$^{93}$ Over the previous decades, Child-Pugh classification has been utilized in the guidance of resection candidates. However, Child-Pugh classification is far from accurate in predicting postoperative liver failure and some authors argue that Child-Pugh A patients already have functional liver impairment, significant portal hypertension, and minor fluid retention necessitating diuretic use. ${ }^{94}$ Utilizing the MELD, a score of $\leq 8$ has been shown to have no mortality as compared to a perioperative mortality of $29 \%$ for a score of $>9 .{ }^{95}$ Many Japanese groups rely on the indocyanine green retention test to assess whether surgery is possible. The feasibility of surgery or degree of possible liver resection can be determined by the degree of indocyanine dye retention. In the United States and Europe, selection of ideal candidates for resection is usually based on the assessment of portal hypertension, which is assessed by cannulation of the hepatic vein and calculation of the hepatic portal venous gradient. Significant portal hypertension is evident when the portocaval gradient is $>10 \mathrm{mmHg}$. A significant gradient can also be clinically surmised with evidence of gastroesophageal varices, splenomegaly, and a platelet count $<1 \times 10^{11} / \mathrm{L}$ that leads to an increase in postoperative morbidity and mortality. ${ }^{96}$

Perioperative portal vein embolization (PVE) is a technique utilized to cause hypertrophy of the anticipated residual liver remnant, thus permitting a more extensive liver resection. When PVE is performed, an overall increase in the liver volume of $10 \%-12 \%$ can be achieved. ${ }^{97}$ Perioperative PVE has less major complications (10\% vs 36\%) and 90-day mortality ( $0 \%$ vs $18 \%$ ) compared to patients who have had major resection without PVE. ${ }^{98}$

Postresection 5-year survival rates range from $41 \%$ to $74 \%$ for patients who have a solitary tumor confined to the liver without radiologic evidence of vascular invasion and preserved liver function. ${ }^{17,99,100}$ In contrast, patients who exhibit significant portal hypertension will develop postoperative decompensation with a 5-year survival rate of $<50 \%$. Finally, survival in patients who exhibit both adverse predictors (portal hypertension and elevated bilirubin) and multifocal disease is $<30 \%$ at 5 years. ${ }^{101,102}$ Cirrhotic patients have a perioperative mortality rate between $3 \%$ and $8 \%$ after resection, and a 5-year survival rate ranging from $30 \%$ to $50 \% .{ }^{96}$ Despite increasing overall survival in patients undergoing hepatic resection (HR) to treat HCC, the diseasefree survival has not changed. ${ }^{103}$ Recurrence rates may be as high as $70 \%$ after 5 years. Predictors of early recurrence include AFP levels $>2,000 \mathrm{ng} / \mathrm{dL}$, nonanatomic resection, micro- or macrovascular invasion, positive resection margins, and poorly differentiated tumors. ${ }^{104}$ While de novo tumor development can occur after resection, the majority of $\mathrm{HCC}$ recurrences occurs within 1-2 years and is believed to be a result of dissemination or micrometastasis from the primary tumor and not inadequate surgical resection. ${ }^{2}$ Contraindications to resection are the presence of extrahepatic metastasis or invasion of the main portal trunk by the tumor. Generally, neoplastic invasion of the portal vein leading to thrombosis is a poor prognostic indicator; however, in certain cases, hemihepatectomy can be feasible, especially when thrombosis of the main branch of the portal vein resulted in the hypertrophy of the contralateral hemiliver. ${ }^{105}$

In comparison to traditional open surgery, laparoscopic liver resection is safe $\mathrm{e}^{106,107}$ and effective in cirrhotic patients and now plays a key role in the treatment of HCC. Resection is also the primary treatment for advanced tumors and can be used as an alternative or a bridge to liver transplantation. ${ }^{108-111}$ Technical feasibility is the only limiting factor when offering laparoscopic vs open resection. Two criteria have been proposed to assist in the selection of appropriate candidates for surgery: size and location of the tumor and liver function. ${ }^{112}$

\section{Liver transplantation}

Orthotopic liver transplantation (OLT) is the best curative option for patients with decompensated cirrhosis, and HCC is the only solid cancer that can be treated with transplantation. Mazzaferro et al $^{113}$ published a landmark study with $<50$ patients who were transplanted for HCC with specific criteria, which became known as the Milan criteria. These specific criteria included single $\mathrm{HCC}$ tumors $<5 \mathrm{~cm}$ or three tumors all $\leq 3 \mathrm{~cm}$ each and demonstrated a 4-year survival rate of $75 \%$. A recent systemic review of 90 studies that followed 17,780 
patients over a 15-year period identified the Milan criteria as an independent prognostic factor of outcome after OLT. ${ }^{114}$

Expansion of the Milan criteria, particularly by liberating the restrictions on tumor size, has also been studied. The University of California San Francisco (UCSF) criteria, which includes 1) a single lesion $\leq 6.5 \mathrm{~cm}$, or 2) three or fewer nodules with the largest lesion $\leq 4.5 \mathrm{~cm}$ and with a total diameter $\leq 8 \mathrm{~cm}$, have been studied both retrospectively and prospectively and have shown survival and recurrence rates equal to those patients using the Milan Criteria. ${ }^{49}$ The 1 - and 5-year survival rates were $90 \%$ and $75 \%$, respectively. ${ }^{115}$ Both the Milan and UCSF criteria consider the number and size of the tumor regardless of tumor biology. The University of Toronto developed a protocol for biopsying large tumors up to $10 \mathrm{~cm}$, and poorly differentiated tumors were excluded. These patients were treated aggressively prior to transplantation with ablative therapies, with survival being similar in both the Milan criteria and expanded criteria patients. ${ }^{116}$

Locoregional therapies have been used to downsize patients with $\mathrm{HCC}$ exceeding current transplant criteria with the goal to decrease the tumor burden in order to meet transplant criteria. ${ }^{117-119}$ Yao et al ${ }^{119}$ published a downstaging protocol consisting of transarterial chemoembolization (TACE) and/or radiofrequency ablation (RFA) and demonstrated survival rates of $96.2 \%$ at 1 year and $92.1 \%$ at 4 years among patients who received transplantation. In compensated livers, locoregional therapy is utilized to downsize the tumor to an acceptable size and within standard criteria. Posttransplant survival data are comparable in patients who underwent downsizing with those within conventional criteria. ${ }^{118}$ Ablative therapies can also be used as bridging therapies for transplantation, deceleration of tumor progression, minimization of dropout, and improvement of posttransplant survival. ${ }^{8}$ Long waiting time, and a shortage in available organs, is one of the major disadvantages of OLT as a treatment option in HCC. Under the current United Network of Organ Sharing policy, patients who are diagnosed with HCC and are within the Milan criteria receive a MELD score of 22 . This starting score increases in a stepwise fashion every 3 months after the results of repeated imaging (CT or $\mathrm{MRI})$ reconfirm that criteria is still met. ${ }^{120}$ This can result in a waiting time of $>2$ years in certain areas of the country. An alternative to deceased donor liver transplantation is living donor liver transplantation; however, the mortality to the donor is approximately $0.3 \%$ and life-threatening morbidity is $2 \%$. Because of the risk to the donor, living donor liver transplantation should be restricted to centers of excellence. ${ }^{121}$

\section{Nonsurgical approaches}

Transarterial chemoembolization

The most commonly used initial treatment for locoregional HCC as well as for downstaging tumors that exceed criteria is TACE. ${ }^{122}$ TACE can also be considered prior to HR and RFA as neoadjuvant therapy to either reduce tumor volume or even target micrometastasis. ${ }^{123}$ The rationale for using TACE is the neoangiogenic properties of HCC and its mechanism of action on the hepatic arterial supply of the tumor. During its initial development, the tumor derives its blood flow from the portal system. As the tumor increases in size, the blood supply becomes arterialized, so even a well-differentiated HCC is mostly dependent on hepatic arterial supply. This tumor characteristic provides the pathologic basis for the radiologic features used to diagnose HCC. Embolization of the hepatic artery branch leads to selective tumor hypoxia and eventually tumor necrosis. This is accomplished by a significant reduction in arterial blood flow through the use of image-guided catheter-based infusion of particles. ${ }^{124}$ Potential agents including polyvinyl alcohol beads, alcohol, starch microspheres, metallic coils, autologous blood clots, and gelfoam have all been used for embolization. ${ }^{5}$ Prior to arterial embolization, a chemotherapeutic agent is injected. Several chemotherapeutic agents have been historically used, including doxorubicin, cisplatin, mitomycin, and epirubicin. $^{2}$ In addition, doxorubicin-eluding beads have recently become an alternative to traditional TACE. Drug-eluding beads are considered an improvement in both treatment response rates and tumor necrosis compared to traditional TACE. ${ }^{125}$ Contraindications for TACE are decompensating cirrhosis (Child-Pugh B), massive tumor with extensive replacement of both lobes, severely reduced portal flow (portal vein occlusion or hepatofugal blood flow), and a creatinine clearance of $<30 \mathrm{~mL} / \mathrm{min} .{ }^{126}$ Llovet et al ${ }^{127}$ found that survival probabilities for TACE were $82 \%$ and $63 \%$ for 1 and 2 years, respectively, for unresectable HCC. The response to TACE is an independent predictor of survival. Additional studies have shown an improvement in survival in TACE-treated patients in the range of $20 \%-60 \%$ at 2 years. ${ }^{128}$ Morbidity with embolization is relatively low $(<5 \%)$, and common complications include abdominal pain, nausea, ileus, and fever, which are consistent with postembolization syndrome. ${ }^{129}$ Historically, portal vein tumor thrombosis has been considered a contraindication to the performance of TACE therapy. This interruption of hepatic arterial blood flow which can lead to significant hepatic necrosis when combined with a portal vein occlusion from tumor thrombus which already compromised blood flow to the affected area of the liver. Several prospective and reactive retrospective 
studies have shown that TACE can improve overall survival in Child-Pugh's A cirrhotic HCC patients with portal vein tumor thrombosis. Furthermore, the combination of TACE and sorafenib may have synergistic value. ${ }^{130}$

\section{Transartetial radiation}

Transartetial radioembolization is a form of catheter-directed internal radiation that delivers small microspheres with radioisotopes directly into the tumor. Yttrium-90 (Y-90) microspheres or iodine-131-labeled lipiodol ${ }^{127}$ are administered in a procedure similar to TACE. This procedure has been shown to be safe and effective in cirrhotic patients with HCC. ${ }^{131,132}$ One major advantage of Y-90 over TACE is that it is indicated in the case of portal vein neoplastic thrombosis, while TACE traditionally has been considered a contraindication. ${ }^{133}$ The side effects are usually well tolerated. ${ }^{134}$ The most common side effects include fatigue, nausea and vomiting, and abdominal pain. Postembolization syndrome (fever, unremitting nausea, general malaise, loss of appetite, and abdominal pain) is seen less frequently with TACE. A pretreatment evaluation that often includes an arteriogram, superior mesenteric angiogram, and celiac trunk angiogram is necessary to evaluate for the presence of arterioportal shunting. Coil embolization of these colateral vessels may be necessary to decrease unintended deposition of microspheres outside the targeted area. Vessels most often embolized include the inferior esophageal, left inferior phrenic, accessory left gastric, supraduodenal, and retroduodenal arteries. Y-90 is contraindicated in patients with hepatopulmonary shunting, which can lead to extremely high levels of pulmonary radiation exposure and the development of radiation pneumonitis. The reported rate of complete tumor necrosis in patients with tumors $<3 \mathrm{~cm}$ was $90 \% .{ }^{91}$ The 2010 AASLD clinical practice guidelines stated that radioembolization with Y-90 glass beads has been shown to induce extensive tumor necrosis with an acceptable safety profile; however, no studies demonstrating an impact on survival have been established. ${ }^{5}$

\section{Percutaneous local ablation}

Percutaneous local ablation, which includes both RFA and percutaneous ethanol injection, is the standard of care for BCLC stage 0-A HCC not suitable for surgery. ${ }^{2}$ RFA is the treatment of choice for local destruction of liver tumors. RFA produces coagulative necrosis of the tumor while leaving a safety margin around the tumor, leading this to be the most common local ablative therapy. RFA can be performed both percutaneously under radiological guidance using CT or US or during surgery guided by intraoperative US. Complete ablation of tumors $<2 \mathrm{~cm}$ is possible in $>90 \%$ of cases. ${ }^{135}$ There are several limitations of RFA:

1. for tumors $>3 \mathrm{~cm}$, complete necrosis is rarely observed;

2. there is difficulty in ablating tumors that are adjacent to major blood vessels;

3. it is difficult to reach certain segments of the liver (ie, Segment 1) percutaneously;

4. subcapsular lesions can rupture into peritoneum;

5. bladder injury can occur with ablation of segment IVb; and

6. in livers with multinodular cirrhosis, targeting lesions under ultrasound guidance can be difficult. ${ }^{105}$

The treatment of HCC has been well demonstrated in multiple series with overall 5-year survival rates between 33\% and $55 \% .{ }^{136}$ Ethanol injection requires multiple injections on separate days and rarely induces significant necrosis in tumors $>3 \mathrm{~cm}$ largely because the injected ethanol rarely reaches the entire tumor volume. Tumor necrosis rates are $90 \%-100 \%$ for tumors $<2 \mathrm{~cm}, 70 \%$ for 2 - and $3-\mathrm{cm}$ tumors, and $50 \%$ in $\mathrm{HCC}$ tumors between 3 and $5 \mathrm{~cm} .^{5}$ In one prospective nonrandomized study, RFA achieved higher ablation rates on $\mathrm{HCC}$ tumors $<3 \mathrm{~cm}$ than percutaneous ethanol injection $(90 \%$ vs $80 \%)$ with fewer treatments.

\section{Microwave ablation}

Microwave ablation (MWA) can be utilized both percutaneously and intraoperatively and is a potentially curative ablative procedure. ${ }^{137}$ It is a method very similar to RFA, except MWA utilizes electromagnetic waves with frequencies $>900$ $\mathrm{kHz}$ to irradiate and ablate tumor foci. ${ }^{90}$ This leads to rapid elevation of temperatures within the MWA field to excess of $100^{\circ} \mathrm{C}$ without the damaging effects of tissue impedance, leading to a more rapid and uniform ablation. ${ }^{53}$ This carries an increased risk of more severe injury to adjacent structures when compared to RFA. Earlier studies comparing MWA and RFA demonstrated no statistical difference in efficiency, and more recent studies using improved MWA modalities show potential. ${ }^{90}$ Clinical advantage of MWA over RFA and its potential to demonstrate increased rates of tumor necrosis with a reduction in overall treatments need to be evaluated.

\section{Systemic therapy}

The majority of patients diagnosed with HCC present with advanced disease. Prior to 2008, no systemic therapy was available that demonstrated an improvement in survival. With the publication of two randomized placebo-controlled Phase III trials, the oral multitargeted tyrosine kinase inhibitor 
sorafenib has become the new standard of treatment for advanced HCC with an increased median survival from 7.9 months in the placebo group to 10.7 months in the treatment group. ${ }^{138,139}$ Sorafenib blocks the activity of Raf serine/ threonine kinase isoforms, as well as the receptor tyrosine kinases vascular endothelial growth factor receptor 2 and 3 , platelet-derived growth factors receptor $\beta$, c-KIT, FLT-3, and RET, to inhibit tumor angiogenesis and tumor cell proliferation. ${ }^{140}$ Currently, sorafenib is recommended in patients with advanced HCC and preserved liver function who are not candidates for either resection or liver transplantation and have failed to respond to locoregional therapies. ${ }^{141}$ The main side effects include anorexia, nausea, vomiting, weight loss, hoarseness of voice, esthesia, and hypertension. ${ }^{142}$ Sorafenib can be difficult to tolerate because of the side effect profile, dose reduction (54\%) or treatment interruption ( $40 \%$ ) is often needed. ${ }^{143}$ Despite the side effects, treatment is recommended to be continued until progression of the tumor is demonstrated. Currently, studies are continuing in an attempt to identify the best responders to sorafenib; c-Jun N-terminal kinase activity was positively correlated with the CD133 expression level and inversely correlated with the therapeutic response to sorafenib. ${ }^{105}$ Consequently, c-Jun N-terminal kinase activity may be considered as a new predictive biomarker for response to sorafenib. ${ }^{101}$

\section{Conclusion}

$\mathrm{HCC}$ is an aggressive cancer that occurs in the setting of chronic liver disease and cirrhosis that frequently presents in advanced stages. Concomitant liver dysfunction with advanced tumor stages further impedes curative therapies. HCC as well as other cancers, can be prevented if appropriate measures, including HBV vaccination, universal screening of blood products, use of safe injection practices, treatment and education of alcoholics and intravenous drug users, and initiation of antiviral therapy, have shown to be effective. ${ }^{102,144}$

Continued improvement in both surgical and nonsurgical approaches has demonstrated significant benefits in overall survival. While OLT remains the only curative surgical procedure, the shortage of available organs precludes this therapy for many patients with HCC. Sorafenib has shown to be a unique neoantigenic targeting agent with encouraging results. Studies need to further investigate other biomarkers both alone and in conjunction with other modalities to assess survival and tumor regression.

\section{Disclosure}

The authors report no conflicts of interest in this work.

\section{References}

1. Center for Disease Control and Prevention (CDC). Hepatocellular carcinoma-United States 2001-2006. MMWR Morb Mortal Wkly Rep. 2010; 59(17):517-520.

2. Crissien AM, Frenette C. Current Management of hepatocellular carcinoma. Gastroenterol Hepatol. 2014;10(3):153-161.

3. Ferlay J, Shin HR, Bray F, Forman D, Mathers C, Parkin DM. Estimates of worldwide burden of cancer in 2008: GLOBOCAN 2008. Int J Cancer. 2010;127(12):2893-2971.

4. Altekruse SF, McGlynn KA, Reichman ME. Hepatocellular carcinoma incidence, mortality and survival trends in the United States from 1975 to 2005. J Clin Oncol. 2009;27:1485-1491.

5. Bruix J, Sherman M. AASLD Practice Guidelines: management of hepatocellular carcinoma: an update. Hepatology, 2010:1-35.

6. Ott JJ, Stevens GA, Groeger J, Wiersma ST. Global epidemiology of hepatitis B virus infection: new estimates of age-specific HBsAg seroprevalence and endemicity. Vaccine. 2012;30(12):2212-2219.

7. International Agency for Research on Cancer (IARC). Monographs on the evaluation of carcinogenic risks to humans. Hepatitis Viruses. 1994;59:182-221.

8. McMahon BJ. The natural history of chronic hepatitis B virus infection. Hepatology. 2009;49(5):S45-S55.

9. Chen G, Lin W, Shen F, Iloeje UH, London WT, Evans AA. Past HBV viral load as predictor of mortality and morbidity from $\mathrm{HCC}$ and chronic liver disease in a prospective study. Am J Gastroenterol. 2006;101(8): 1797-1803.

10. Hosaka T, Suzuki F, Kobayashi M, et al. Long-term entecavir treatment reduces hepatocellular carcinoma incidence in patients with hepatitis B virus infection. Hepatology. 2013;58(1):98-107.

11. Chiang C-J, Yang Y-W, You S-L, Lai M-S, Chen C-J. Thirty-year outcomes of the national hepatitis B immunization program in Taiwan. JAMA. 2013;310(9):974-976.

12. Goldstein ST, Zhou F, Hadler SC, Bell BP, Mast EE, Margolis HS. A mathematical model to estimate global hepatitis B disease burden and vaccination impact. Int J Epidemiol. 2005;34(6):1329-1339.

13. Deng M, Zhou X, Gao S, et al. The effects of telbivudine in late pregnancy to prevent intrauterine transmission of the hepatitis B virus: a systematic review and meta-analysis. Virol J. 2012;9:185.

14. Wu Q, Huang H, Sun X, et al. Telbivudine prevents vertical transmission of hepatitis B virus from women with high viral loads: a prospective long-term study. Clin Gastroenterol Hepatol. 2015;13(6):1170-1176.

15. Choo QL, Richman KH, Han JH, et al. Genetic organization and diversity of the hepatitis C virus. Proc Natl Acad Sci USA. 1991;88(6): 2451-2455.

16. Bostan N, Mahmood T. An overview about hepatitis C: a devastating virus. Crit Rev Microbiol. 2010;36(2):91-133.

17. Asham EH, Kaseb A, Ghobrial RM. Management of hepatocellular carcinoma. Surg Clin North Am. 2013;(9):1423-1450.

18. Lok AS, Seeff LB, Morgan TR, et al. Incidence of hepatocellular carcinoma and associated risk factors in hepatitis C-related advanced liver disease. Gastroenterology. 2009;136(1):138-148.

19. Gao C, Fang L, Zhao HC, Li JT, Yao SK. Potential role of diabetes mellitus in the progression of cirrhosis to hepatocellular carcinoma: a crosssectional case-control study from Chinese patients with HBV infection. Hepatobiliary Pancreat Dis Int. 2013;12(4):385-393.

20. Puoti M, Bruno R, Soriano V, et al. Hepatocellular carcinoma in HIVinfected patients: epidemiological features, clinical presentation and outcome. AIDS. 2004;18(17):2285-2293.

21. Singal AK, Anand BS. Mechanisms of synergy between alcohol and hepatitis C virus. J Clin Gastroenterol. 2007;41(8):761-772.

22. Morgan RL, Baack B, Smith BD, Yartel A, Pitasi M, Falck-Ytter Y. Eradication of hepatitis $\mathrm{C}$ virus infection and the development of hepatocellular carcinoma: a meta-analysis of observational studies. Ann Intern Med. 2013;158(5):329-337.

23. International Agency for Research on Cancer (IARC). Monographs on the evaluation of carcinogenic risks to humans. Alcohol Drinking. 1998;44(44):207-215. 
24. Batey RG, Burns T, Benson RJ, Byth K. Alcohol consumption and the risk of cirrhosis. Med J Aust. 1992;156:413-416.

25. Morgan TR, Mandayam S, Jamal MM. Alcohol and hepatocellular carcinoma. Gastroenterology. 2004;127(5):S87-S96.

26. Jewell J, Sheron N. Trends in European liver death rates: implications for alcohol policy. Clin Med. 2010;10(3):259-263.

27. Brechot C, Nalpas B, Feitelson MA. Interactions between alcohol and hepatitis viruses in the liver. Clin Lab Med. 1996;16:273-287.

28. Hassan MM, Hwang LY, Hatten CJ, et al. Risk factors for hepatocellular carcinoma: synergism of alcohol with viral hepatitis and diabetes mellitus. Hepatology. 2002;36(5), 1206-1213.

29. Turati F, Galeone C, Rota M, et al. Alcohol and liver cancer: a systematic review and meta-analysis of prospective studies. Ann Oncol. 2014; 25(8):1526-1535.

30. Rinella ME. Nonalcoholic fatty liver disease: a systematic review. JAMA. 2015;313(22):2263-2273

31. Wang C, Wang X, Gong G, et al. Increased risk of hepatocellular carcinoma in patients with diabetes mellitus: a systematic review and meta-analysis of cohort studies. Int J Cancer. 2012;130(7):1639-1648.

32. Wong RJ, Cheung R, Ahmed A. Nonalcoholic steatohepatitis is the most rapidly growing indication for liver transplantation in patients with hepatocellular carcinoma in the U.S. Hepatology. 2014;59(6): 2188-2195.

33. El-Serag HB, Hampel H, Javadi F. The association between diabetes and hepatocellular carcinoma: a systemic review of epidemiologic evidence. Clin Gastroenterol Hepatol. 2006;4:369-380.

34. Moore MA, Park CB, Tsuda H. Implications of the hyperinsulinaemia-diabetes-cancer link for preventive efforts. Eur J Cancer Prev. 1998;7(2):89-107.

35. Balkau B, Kahn H, Courbon D, Eschwege E, Ducimetiere P; Paris Prospective Study. Hyperinsulinemia predicts fatal liver cancer but is inversely associated with fatal cancer at some other sites: the Paris Prospective Study. Diabetes Care. 2001;24(5):843-849.

36. Callee EE, Rodriguez C, Walker-Thurmond K, Thun MJ. Overweight, obesity and mortality from cancer in a prospective studied cohort of US adults. $N$ Engl J Med. 2003;348:1625-1638.

37. Reddy JK, Rao MS. Lipid metabolism and liver inflammation. Am J Physiol Gastrointest Liver Physiol. 2006;290:G852-G858.

38. Larson SC, Wolk A. Overweight, obesity and risk of liver cancer: a meta-analysis of cohort studies. Br J Cancer. 2007;97:1005-1008.

39. Monsour HP, Asham E, McFadden RS, Victor DW, Muthuswamy B, Zaheer I. Hepatocellular carcinoma: the rising tide from east to west $-\mathrm{a}$ review of epidemiology, screening and tumor markers. Transl Cancer Res. 2013;2(6):492-506.

40. Wakai T, Shirai Y, Sakata J, Korita PV, Ajioka Y, Hatakeyama, K. Surgical outcomes for hepatocellular carcinoma in nonalcoholic fatty liver disease. J Gastrointest Surg. 2011;15(8):1450-1458.

41. Tokushige K, Hashimoto E, Yatsuji S, et al. Prospective study of hepatocellular carcinoma in nonalcoholic steatohepatitis in comparison with hepatocellular carcinoma caused by chronic hepatitis C.J Gastroenterol. 2010;45(9):960-967.

42. White DL. Epidemiology of hepatocellular carcinoma. In: Carr BI, editor. Hepatocelluar Carcinoma. New York, NY: Humana Press; 2010:1-25.

43. Yuan J-M, Ross R, Stanczyk FZ, et al. A cohort study of serum testosterone and hepatocellular carcinoma in Shanghai, China. Int J Cancer. 1995; 63(4):491-493.

44. White DL, Tavakoli-Tabasi S, Kuzniarek J, Pascua R, Ramsey DJ, El-Serag HB. Higher serum testosterone is associated with increased risk of advanced hepatitis C-related liver disease in males. Hepatology. 2012; 55(3):759-768.

45. Liu Y, Wu F. Global burden of aflatoxin-induced hepatocellular carcinoma: a risk assessment. Environ Health Perspect. 2010;118(6):818-824.

46. Chen JG, Egner PA, Ng D, et al. Reduced aflatoxin exposure presages decline in liver cancer mortality in an endemic region of China. Cancer Prev Res. 2013;6(10):1038-1045.
47. Ko C, Siddaiah N, Berger J, et al. Prevalence of hepatic iron overload and association with hepatocellular cancer in end-stage liver disease: results from the National Hemochromatosis Transplant Registry. Liver Int. 2007; 27(10):1394-1401.

48. DeugnierY, Turlin B. Iron and hepatocellular carcinoma. J Gastroenterol Hepatol. 2001;16(5):491-494.

49. Gandini S, Botteri E, Iodice S, Boniol M, Lowenfels AR, Maisonneuve P. Tobacco smoking and cancer: a meta-analysis. Int J Cancer. 2008;122: $155-164$.

50. Maheshwari S, Sarraj A, Kramer J, El-Serag HB. Oral contraception and the risk of hepatocellular carcinoma. J Hepatol. 2007;47:506-513.

51. van Meer S, de Man RA, Coenraad MJ, et al. Surveillance for hepatocellular carcinoma is associated with increased survival: results from a large cohort in the Netherlands. J Hepatol. 2015;63(5):1156-1163.

52. Zhang BH, Yang BH, Tang ZY. Randomized controlled trial of screening for hepatocellular carcinoma. J Cancer Res Clin Oncol. 2004; 130(7):417-422.

53. Bruix J, Sherman M; American Association for the Study of Liver Diseases. AASLD Practice Guideline: management of hepatocellular carcinoma: an update. Hepatology. 2011;53(2):1020-1022.

54. Trevisani F, Santi V, Gramenzi A, et al. Surveillance for early diagnosis of hepatocellular carcinoma: is it effective in intermediate/advanced cirrhosis? Am J Gastroenterol. 2007;102(11):2248-2257.

55. Masuzaki R, Omata M. Screening program in high-risk populations. Hepatocellular Carcinoma; 2011:55-68.

56. Lok AS, Heathcote EJ, Hoofnagle JH. Management of hepatitis B: 2000 - summary of a workshop. Gastroenterology. 2001;120(7):1828-1853.

57. Kew MC, Macerollo P. Effect of age on the etiologic role of the hepatitis B virus in hepatocellular carcinoma in blacks. Gastroenterology. 1988;94(2):439-442.

58. Yu MW, Chang HC, Liaw YF, et al. Familial risk of hepatocellular carcinoma among chronic hepatitis B carriers and their relatives. J Natl Cancer Inst. 2000;92(14):1159-1164.

59. Takashima T, Matsui O, Suzuki M, Ida M. Diagnosis and screening of small hepatocellular carcinomas. Comparison of radionuclide imaging, ultrasound, computed tomography, hepatic angiography, and $\alpha 1$-fetoprotein assay. Radiology. 1982;145:635-638.

60. Peterson MS, Baron RL. Radiologica diagnosis of hepatocellular carcinoma. Clin Liver Dis. 2001;5(1):123-144.

61. Bolondi L, Sofia S, Siringo S, et al. Surveillance programme of cirrhotic patients for early diagnosis and treatment of hepatocellular carcinoma: a cost effectiveness analysis. Gut. 2001;48(2):251-259.

62. Achkar JP, Araya V, Baron RL, Marsh JW, Dvorchik I, Rakela J. Undetected hepatocellular carcinoma: clinical features and outcomes after liver transplantation. Liver Transpl Surg. 1998;4:477-482.

63. Brahee DD, Ogedegbe C, Hassler C, et al. Body mass index and abdominal ultrasound image quality: a pilot survey of sonographers. J Diagn Med Sonogr. 2013;29(2):66-72.

64. Wald C, Russo MW, Heimbach JK., Hussain HK, Pomfret EA, Bruix J. New OPTN/UNOS policy for liver transplant allocation: standardization of imaging, diagnosis, classification, and reporting of hepatocellular carcinoma. Radiology. 2013;266(2):376-382.

65. Colli A, Fraquelli M, Casazza G, et al. Accuracy of ultrasonography, spiral CT, magnetic resonance, and alpha-fetoprotein in diagnosing hepatocellular carcinoma: a systematic review. Am J Gastroenterol. 2006;101(3):513-523.

66. Collier J, Sherman M. Screening for hepatocellular carcinoma. Hepatology. 1998;27:273-278.

67. Sherman M, Peltekian KM, Lee C. Screening for hepatocellular carcinoma in chronic carriers of hepatitis B virus: incidence and prevelance of hepatocellular carcinoma in a North American urban population. Hepatology. 1995;22:432-438.

68. Trevisani F, D'Intino PE, Morselli-Labate AM, et al. Serum $\alpha$-fetoprotein for diagnosis of hepatocellular carcinoma in patients with chronic liver disease: influence of HBsAg and anti-HCV status. $J$ Hepatol. 2001;34(4):570-575. 
69. Gambarin-Gelwan M, Wolf DC, Shapiro R, Schwartz ME, Min AD. Sensitivity of commonly available screening tests in detecting hepatocellular carcinoma in hepatitis C virus cirrhosis. Hepatology. 2000; 95:1535-1538.

70. Di Bisceglie AM, Sterling RK, Chung RT, et al. Serum $\alpha$-fetoprotein levels in patients with advanced hepatitis $\mathrm{C}$ : results from the HALT-C Trial. J Hepat. 2005;43(3):434-441.

71. Nguyen MH, Garcia RT, Simpson PW, Wright TL, Keeffe EB. Racial differences in effectiveness of alpha-fetoprotein for diagnosis of hepatocellular carcinoma in hepatitis $\mathrm{C}$ virus cirrhosis. Hepatology. 2002;36(2):410-417.

72. Lin OS, Keeffe EB, Sanders GD, Owens DK. Cost-effectiveness of screening for hepatocellular carcinoma in patients with cirrhosis due to chronic hepatitis C. Aliment Pharmacol Ther. 2004;19(11):1159-1172.

73. Khien VV, Mao HV, Chinh TT, et al. Clinical evaluation of lentil lectin-reactive alpha-fetoprotein-L3 in histology-proven hepatocellular carcinoma. Int J Biol Markers. 2001;16(2):105-111.

74. Ishii M, Gama H, Chida N, et al. Simultaneous measurements of serum $\alpha$-fetoprotein and protein induced by vitamin $\mathrm{K}$ absence for detecting hepatocellular carcinoma. South Tohoku District Study Group. Am J Gastroenterol. 2000;95(4):1036-1040.

75. Marrero JA, Su GL, Wei W, et al. Des- $\gamma$ carboxyprothrombin can differentiate hepatocellular carcinoma from nonmalignant chronic liver disease in American patients. Hepatology. 2003;37(5):1114-1121.

76. Singhal A, Jayaraman M, Dhanasekaran DN, Kohli V. Molecular and serum markers in hepatocellular carcinoma: predictive tools for prognosis and recurrence. Crit Rev Oncol Hematol. 2012;82(2):116-140.

77. Sangiovanni A, Manini MA, Iavarone M, et al. The diagnostic and economic impact of contrast imaging techniques in the diagnosis of small hepatocellular carcinoma in cirrhosis. Gut. 2010;59:638-644.

78. Lee YJ, Lee JM, Lee JS, et al. Hepatocellular carcinoma: diagnostic performance of multidetector CT and MR imaging - a systematic review and meta-analysis. Radiology. 2015;275:97-109.

79. El-Serag HB. Hepatocellular carcinoma. N Engl J Med. 2011;365: 1118-1127.

80. Verslype C, Rosmorduc O, Rougier P; ESMO Guidelines Working Group. Hepatocellular carcinoma: ESMO-ESDO Clinical Practice Guidelines for diagnosis, treatment and follow-up. Ann Oncol. 2012; 23(7):vii42-vii48.

81. Nathan H, Pawlik TM. Staging of hepatocellular carcinoma. In: Masters KM, Vauthey J-N, editors. Hepatocellular Carcinoma. Berlin, Germany: Springer:69-80.

82. Huo TI, Lin HC, Hsia CY, et al. The model for end-stage liver disease based cancer staging systems are better prognostic models for hepatocellular carcinoma: a prospective sequential survey. Am J Gastroenterol. 2007; 102:1920-1930.

83. Kamath PS, Wiesner RH, Malinchoc M, et al. A model to predict survival in patients with end-stage liver disease. Hepatology. 2001; 33(2):464-470.

84. Vauthey JN, Lauwers GY, Esnaola NF, et al. Simplified staging for hepatocellular carcinoma. J Clin Oncol. 2002;20(6):1527-1536.

85. Fleming ID. AJCC/TNM cancer staging for hepatocellular carcinoma. J Surg Oncol. 2001;77:233-236.

86. Sanyal A, Poklepovic A, Moyneur E, Bargout V. (2010). Populationbased risk factors and resource utilization for HCC: US perspective. Curr Med Res Opin. 2010;26(9):2183-2191.

87. Singal AG, Nehra M, Adams-Huet B, et al. (2013). Detection of hepatocellular carcinoma at advanced stages among patients in the HALT-C trial: where did surveillance fail? Am J Gastroenterol. 2013;108(3): 425-432.

88. Forner RM, Rodriguez de Lope C, Bruix J. Current strategy for staging and treatment: the BCLC update and future prospects. Semin Liver Dis. 2010;30:61-74.

89. Allemann P, Demartines N, Bouzourene H, Tempia A, Halkic N. Longterm outcome after liver resection for hepatocellular carcinoma larger than $10 \mathrm{~cm}$. World J Surg. 2013;37(2):452-458.

90. Wong R, Frenette C. Updates in the management of hepatocellular carcinoma. Gastroenterol Hepatol. 2011;7(1):16-24.
91. Ishizawa T, Hasegawa A, Aoki T, et al. Neither multiple tumors nor portal hypertension are surgical contraindications for hepatocellular carcinoma. Gastroenterology. 2008;134(7):1908-1916.

92. Roayaie S, Haim MB, Emre S, et al. Comparison of surgical outcomes for hepatocellular carcinoma in patients with hepatitis B versus hepatitis C: a western experience. Ann Surg Oncol. 2000;7(10):764-770.

93. Colleoni M,Audisio RA, De Braud F, Fazio N, Martinelli G, Goldhirsh A. Practical considerations in treatment of hepatocellular carcinoma. Drugs. 1998;55(3):367-382.

94. D’Amico G, Garcia-Tsao G, Pagliaro L. Natural history and prognostic indicators of survival in cirrhosis: a systemic review of 118 studies. J Hepatol. 2006;44:217-231.

95. Teh SH, Christein J, Donohue J, et al. Hepatic resection of hepatocellular carcinoma in patients with cirrhosis: model of end-stage liver disease (MELD) score predicts perioperative mortality. J Gastrointest Surg. 2005;9(9):1207-1215.

96. Belghiti J, Kianmanesh R. Surgical treatment of hepatocellular carcinoma. HPB. 2005;7:42-49.

97. Abulkhir A, Limongelli P, Healey AJ, et al. Preoperative portal vein embolization for major liver resection: a meta-analysis. Ann Surg. 2008;247(1):49-57.

98. Palavecino M, Chun YS, Madoff DC, et al. Major hepatic resection for hepatocellular carcinoma with or without portal vein embolization: perioperative outcome and survival. Surgery. 2009;145(4):399-405.

99. Poon RT, Fan ST, Lo CM, Liu CI, Wong, J. Long-term survival and pattern of recurrence after resection of small hepatocellular carcinoma in patients with preserved liver function: implications for a strategy of salvage transplantation. Ann Surg. 2002;235:373-382.

100. Toso C, Trotter J, Wei A, et al. Total tumor volume predicts risk of recurrence following liver transplantation in patients with hepatocellular carcinoma. Liver Transpl. 2007;7:1107-1115.

101. Rimassa L, Santoro A. Sorafenib therapy in advanced hepatocellular carcinoma: the SHARP trial. Expert Rev Anticancer Ther. 2009;9(6):739-745.

102. Hagiwara S, Kudo M, Nagai T, et al. Activation of JNK and high expression level of CD133 predict a poor response to sorafenib in hepatocellular carcinoma. Br J Cancer. 2012;106:1997-2003.

103. Au JS, Frenette CT. (2015). Management of hepatocellular carcinoma: current status and future directions. Gut Liver. 2015;9(4):437-448.

104. Imamura H, Matsuyama Y, Tanaka E. Risk factors contributing to early and late phase intrahepatic recurrence of hepatocellular carcinoma after hepatectomy. J Hepatol. 2003;38:200-207.

105. Vivarelli M, Montalti R, Risaliti A. Multimodal treatment of hepatocellular carcinoma on cirrhois: an update. World J Gastroenterol. 2013;19(42):7316-7326.

106. Torzilli G, Makuuchi M, Inoue K, et al. No-mortality liver resection for hepatocellular carcinoma in cirrhotic and noncirrhotic patients: is there a way? A prospective analysis of our approach. Arch Surg. 1999;134(9):984-992.

107. Fan ST, Lo CM, Liu CL, et al. Hepatectomy for hepatocellular carcinoma: toward zero hospital deaths. Ann Surg. 1999;229:322-330.

108. Abdalla EK, Denys A, Hasegawa K, et al. Treatment of large and advanced hepatocellular carcinoma. Ann Surg Oncol. 2008;15(4):979-985.

109. Capussotti L, Ferrero A, Vigano L, Polastri R, Tabone M. Liver resection for HCC with cirrhosis: surgical perspectives out of EASL/AASLD guidelines. Eur J Surg Oncol. 2009;35:11-15.

110. Cherqui D, Laurent A, Mocellin N, et al. Liver resection for transplantable hepatocellular carcinoma: long-term survival and role of secondary liver transplantation. Ann Surg. 2009;250(5):738-746.

111. Cha CH, Ruo L, Fong Y, et al. Resection of hepatocellular carcinoma in patients otherwise eligible for transplantation. Ann Surg. 2003;238(2):315-323.

112. Vigano L, Cherqui D. Laparoscopic liver resection for HCC: a European perspective. Hepatocellular Carcinoma. Berlin, Germany: Springer; 2011:185-206.

113. Mazzaferro V, Regalia E, Doci R, et al. Liver transplantation for the treatment of small hepatocellular carcinoma in patients with cirrhosis. N Engl J Med. 1996;334(11):693-699. 
114. Mazzaferro V, Bhoori S, Sposito C, et al. Milan criteria in liver transplantation for hepatocellular carcinoma: an evidence-based analysis of 15 years of experience. Liver Transpl. 2011;17(2):S44-S57.

115. Yao FY, Ferrell L, Bass NM. Liver transplantation for hepatocellular carcinoma: expansion of tumor size limits does not adversly impact survival. Hepatology. 2001;33:1394-1403.

116. DuBay D, Sandroussi C, Sandhu L, et al. Liver transplantation for advanced hepatocellular carcinoma using poor tumor differentiation on biopsy as an exclusion criteria. Ann Surg. 2011;253:166-172.

117. Yao FY. Expanded criteria for hepatocellular carcinoma: downstaging with a view to liver transplantation - yes. Semin Liver Dis. 2006;26(3):239-247.

118. Yao FY, Hirose R, LaBerge JM, et al. A prospective study on downstaging of hepatocellular carcinoma prior to liver transplantation. Liver Transpl. 2005;11(12):1505-1514.

119. Yao FY, Kerlan RK, Hirose R, et al. (2008). Excellent outcomes following down-staging of hepatocellular carcinoma prior to liver transplantation: an intention-to-treat analysis. Hepatology. 2008;48(3): 819-827.

120. US Department of Health and Human Services, Health Resources and Services Administration, Organ Procurement and Transplantation Network. (n.d.). Retrieved January 1, 2015. Available from: http://optn.transplant. hrsa.gov/policiesAndBylaws/policies.asp. Accessed May 19, 2016.

121. Mancuso A. Management of hepatocellular carcinoma: enlightening the gray zones. World J Hepatol. 2013;5(6):302-310.

122. Takayasu K, Arii S, Ikai I, et al. Prospective cohort study of transarterial chemoembolization for unresectable hepatocellular carcinoma in 8,510 patients. Gastroenterology. 2006;131:461-469.

123. Schwartz M, Roayaie S, Konstadoulakis M. Strategies for the management of hepatocellular carcinoma. Nat Clin Pract Oncol. 2007;4:424-432.

124. Lewandowski RJ, Geschwind JF, Liapi E, Salem R. Transcatheter intraarterial therapies: rationale and overview. Radiology. 2011; 259(3):641-657.

125. Lammer J, Malagari K, Vogl T, et al. Prospective randomized study of doxorubicin-eluting-bead embolization in the treatment of hepatocellular carcinoma: results of PRECISION V study. Cardiovasc Intervent Radiol. 2010;33(1):41-52.

126. Raoul JL, Sangro B, Forner A, et al. Evolving strategies for the management of intermediate-stage hepatocellular carcinoma: available evidence and expert opinion on the use of transarterial chemoembolization. Cancer Treat Rev. 2011;37(3):212-220.

127. Llovet JM, Real MI, Montana X, et al. Arterial embolization or chemoembolisation versus symptomatic treatment in patients with unresectable hepatocellular carcinoma: a randomized controlled trial. Lancet. 2002;359(9319):1734-1739.

128. Llovet JM, Bruix J. Systematic review of randomized trials for unresectable hepatocellular carcinoma. Hepatology. 2003;37(2):429-442.

129. Tinkle CL, Haas-Kogan D. Hepatocellular carcinoma:natural history, current management, and emerging tools. Biologics. 2012;6: 207-219.
130. Yu SJ, Kim YJ. Effective treatment strategies other than sorafenib for the patients with advanced hepatocellular carcinoma invading portal vein. World J Hepatol. 2015;7(11):1553-1561.

131. Raoul JL, Guyader D, Bretagne JF, et al. Prospective randomized trial of chemoembolization versus intra-arterial injection of 131I-labelediodized oil in the treatment of hepatocellular carcinoma. Hepatology. 1997;26:1156-1161.

132. Sangro B, Carpanese L, Cianni R, et al. Survival after yttrium-90 resin microsphere radioembolization of hepatocellular carcinoma across Barcelona liver cancer stages: a European evaluation. Hepatology. 2011;54(3):868-878

133. Vente MA, Wondergam M, van der Tweel I, et al. Yttrium-90 microsphere radioembolization for the treatment of liver malignancies: a structured meta-analysis. Eur Radiol. 2009;19:951-959.

134. Kulik LM, Carr BI, Mulcahy MF, et al. Safety and efficacy of 90Y radiotherapy for hepatocellular carcinoma with and without portal vein thrombosis. Hepatology. 2008;47(1):71-81.

135. Riaz A, Kulik L, Lewandowski RJ, et al. Radiologic-pathologic correlation of hepatocellular carcinoma treated with internal radiation using yttirum-90 microspheres. Hepatology. 2009;49:1185-1193.

136. Livraghi T, Meloni F, Di Stasi M, et al. Sustained complete response and complications rates after radiofrequncy ablation of very early hepatocellular carcinoma in cirrhosis: is resection still the treatment of choice? Hepatology. 2008;47:82-89.

137. Lencioni R, Cioni D, Crocetti L, et al. Early-stage hepatocellular carcinoma in patients with cirrhosis: long-term results of percutaneous image-guided radiofrequency ablation. Radiology. 2005;234:961-967.

138. Bertot LC, Sato M, Tateishi R, Yoshida H, Koike K. Mortality and complication rates of percutaneous ablative techniques for the treatment of liver tumors: a systemic review. Eur Radiol. 2011;21:2584-2596.

139. Llovet JM, Ricci S, Mazzaferro V, et al. Sorefenib in advanced hepatocellular carcinoma. N Engl J Med. 2008;359(4):378-390.

140. Cheng AL, Kang YK, Chen Z, et al. Efficacy and safety of sorafenib in patients in the Asia-Pacific region with advanced hepatocellular carcinoma: a phase III randomized, double-blind, placebo controlled trial. Lancet Oncol. 2009;10(1):25-34.

141. Bruix J, Raoul J-L, Sherman M, et al. Efficiancy and safety of sorafenib in patients with advanced hepatocellular carcinoma: subanalysis of a phase III trial. J Hepatol. 2012;57:821-829.

142. European Association For The Study OfThe Liver, European Organisation For Research And Treatment Of Cancer. EASL-EORTC clinical practice guidelines: management of hepatocellular carcinoma. $J$ Hepatol. 2012;56:908-943.

143. Iavarone M, Cabibbo G, Piscaglia F, et al. Field-practice study of sorafenib therapy for hepatocellular carcinoma: a prospective multicenter study in Italy. Hepatology. 2011;54(6):2055-2063.

144. Sohal DP, Sun W. Hepatocellular carcinoma: prevention and therapy. Curr Oncol Rep. 2011;13(3):186-194.

145. Cochrane Miller J. Bridging procedures prior to liver transplantation. Radiology Rounds. 2015;13(1).
Journal of Hepatocellular Carcinoma

\section{Publish your work in this journal}

The Journal of Hepatocellular Carcinoma is an international, peerreviewed, open access journal that offers a platform for the dissemination and study of clinical, translational and basic research findings in this rapidly developing field. Development in areas including, but not limited to, epidemiology, vaccination, hepatitis therapy, pathology and
Dovepress

molecular tumor classification and prognostication are all considered for publication. The manuscript management system is completely online and includes a very quick and fair peer-review system, which is all easy to use. Visit http://www.dovepress.com/testimonials.php to read real quotes from published authors. 